\section{Auf dem aktuellen Stand der Forschung}

$S_{\text {in }}$ chwindel und Hörstörungen können in jedem Alter auftreten und gehören zu den häufig geklagten Symptomen in der HNO-Praxis.

In diesem Buch stellen führende Experten aus dem deutschsprachigen Raum ausführlich und auf verständliche Weise die modernen Möglichkeiten der Schwindelbehandlung und der Wiederherstellung der Hörfunktion dar und bringen den Leser auf den aktuellen Stand der Forschung und Entwicklung.
Dabei reicht die Spannbreite von den theoretischen Grundlagen über die diagnostischen Möglichkeiten bis hin zu moderner pharmakologischer, operativer und rehabilitativer Therapie.

Fachleute der Hör- und Gleichgewichtsforschung sowie Experten aus den Bereichen der Seefahrt, des Tauchsports, des Bergsteigens und der Raumfahrt beleluchten die Besonderheiten des Hör- und Gleichgewichtssystems, das gerade durch das moderne Freizeitver-

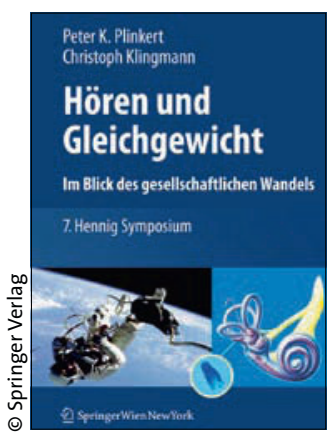

P.K. Plinkert, C. Klingmann (Hrsg.) Hören und Gleichgewicht Springer Verlag 2010 289 Seiten 59,95 Euro ISBN: 978-3-21199269-2

halten, das sich immer mehr in Grenzbereiche begibt, in besonderem Maße gefordert und gefährdet ist.

\section{Standardwerk zur Dysphagie in neuer, überarbeiteter Auflage}

D as Standardwerk zum Thema Dysphagie, das nun in der 4. Auflage erschienen ist, vereinigt Beiträge der verschiedensten ärztlichen und therapeutischen Fachgruppen, die sich mit dem Symptomkomplex Schluckstörungen befassen. Die Überarbeitung integriert zudem neue Forschungsarbeiten, so dass sich die Anschaffung des Buches für jeden lohnt, der auf dem neuesten wissenschaftlichen Kenntnisstand beim Thema
Dysphagie bleiben will. Klinik und Praxis der Krankheitsbilder werden ausführlich beschrieben und detaillierte Anamnese- und Untersuchungsbögen vorgestellt. Das Werk spannt den Bogen von der Physiologie und Pathophysologie des Schluckvorgangs über die klinische, endoskopische, radiologische und manometrische Diagnostik bis hin zu den Therapieoptionen, die unter den Aspekten der evidenzbasierten Medizin

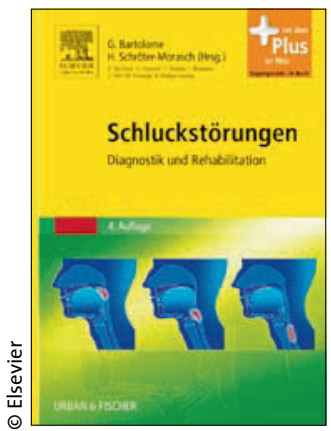

G. Bartolome, H. Schröter-Morasch (Hrsg.)

Schluckstörungen Elsevier 2010 472 Seiten 72,95 Euro ISBN: 978-3437-47161-2

verglichen werden. Die neue Auflage enthält zudem noch mehr farbige und kolorierte anatomische Abbildungen.gz

\title{
Matt und elend lag er da
}

B erühmte Kranke und ihre schlechten Ärzte - eine kleine Geschichte des Ärztepfuschs nennt der Autor dieses spannende, witzige und informative Buch, in dem er eine Menge entsprecher Beispiele zusammengetragen hat.

So hätte etwa Beethoven gut und gern noch ein paar Jahre leben können, wäre er nicht bereits mit Mitte 50 an einer ärztlich verordneten Vergiftung gestorben - denn seine Ärzte hatten versucht, ihn ausgerechnet mit hochtoxischem Bleisalz von einer Lungenentzündung zu kurieren. Ob Beethoven, Nietzsche oder van Gogh: Viele große Persönlichkeiten unserer Zeit mussten sich nicht nur mit hartnäckigen und oft rätselhaften Krankheiten herumschlagen, sondern auch mit grandiosen Fehlleistungen ihrer Ärzte. Falsche Diagnosen und Therapien, aber auch Erbschleicherei und heimtückisches Abkassieren waren die Regel. Von solchen Absurditäten erzählt Jörg Zittlau in diesem spannenden, amüsanten und informativen Buch, das man, einmal begonnen

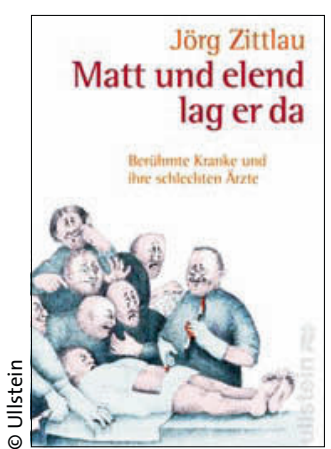

J. Zittlau Matt und elend lag er da Ullstein 2009 224 Seiten 14,90 Euro ISBN: 978-3550-08779-0

zu lesen, nicht mehr aus der Hand legt. Ein ideales Geschenk für einen kollegialen Gabentisch. 